\title{
PREGNANCY WITH SEVERE OLIGOHYDRAMNIOS CAUSING NEONATAL BELL'S PALSY
}

Lakshmikantha. G, Dwarakanath. L, Chaitra S. K, Ananthanarayan Gowda

\author{
1. Assistant professor, department of Obstetrics \& Gynaecology, Sri Siddhartha Medical College, Tumkur, \\ Karnataka, India \\ 2. Associate Professor, department of Obstetrics \& Gynaecology, Sri Siddhartha Medical College, Tumkur, \\ Karnataka, India \\ 3. Resident, department of Obstetrics \& Gynaecology, Sri Siddhartha Medical College, Tumkur, Karnataka, \\ India \\ 4. Assistant professor, department of Pediatrics, Sri Siddhartha Medical College, Tumkur, Karnataka, India
}

\section{CORRESPONDING AUTHOR}

Dr. Lakshmikantha

G, \#249, 3rd A Main,

Near Amba Bhavani circle,

NE of NR Mohalla, Mysore, Karnataka India

E-mail: drlakshmikanthag@yahoo.co.in

Ph: 00919740810611

\begin{abstract}
Neonatal facial palsy is usually associated with difficult forceps delivery. Severe oligohydramnios causing difficult labor and delivery and this leading to congenital facial nerve palsy is a rare phenomenon. We present a very rare phenomenon where there was a congenital facial palsy due to neuropraxia caused by compression of facial nerve due to severe oligohydramnios before onset of labor that was subsequently detected following uncomplicated caesarean delivery. CAPSULE: Severe oligohydramnios with engaged head can lead to lower motor neuron palsy in the neonate due to compression effect.
\end{abstract}

KEYWORDS: neonate, Bell's palsy, oligohydramnios.

INTRODUCTION: Pregnancy with oligohydramnios has many adverse effects on the fetus. These vary depending on the onset of oligohydramnios at different trimesters of pregnancy. We present a rare case of neonate developing transient lower motor neuron type facial palsy following an uncomplicated caesarean section in a pregnancy with severe oligohydramnios.

CASE REPORT: 23 years, primigravida at 40weeks of gestation referred with severe oligohydramnios, not in labor. A thorough obstetric history including history of any infections revealed nothing significant. On examination her vitals were stable, uterus was term size, relaxed, head engaged with right occipito transverse position. Ultrasound revealed AFI 16 at 30 weeks and 2 at admission with normal Doppler study. Non stress test was non reactive.

Emergency Cesarean delivery was performed and delivered the baby without difficulty. Meconium staining of liquor was present. Baby cried after oro nasal suctioning. APGAR score was $7 / 10$ at $1^{\text {st }}$ minute and $8 / 10$ at $5^{\text {th }}$ minute. Baby had deviation of angle of mouth on left side and inability to close the eye on right side. Rest of the examination revealed no abnormality. Baby showed signs of improvement gradually and the facial palsy had disappeared completely by $7^{\text {th }}$ neonatal day. 
DISCUSSION: Congenital facial paralysis accounts for $8-14 \%$ of all pediatric cases of facial paralysis (1). $88 \%$ associated with difficult labor. $67-91 \%$ associated with forceps delivery (2).Oligohydramnios is known to have association with adverse effects on the fetus. Early trimester oligohydramnios causes facial anomalies, pulmonary hypoplasia, limb anomalies etc. Late trimester oligohydramnios lead to cord compression, difficult labor and delivery causing perinatal hypoxia (3). In our case, oligohydramnios developed during late trimester of pregnancy as earlier ultrasonography was normal. Facial nerve is also susceptible to trauma as it exits the stylomastoid foramen where soft tissue compression can lead to transient neuropraxia. This intrauterine trauma can occur from pressure on the infant's face by the sacral prominence during labour (4). Engagement of head at term with severe oligohydramnios could have caused compression on the facial nerve. As it is only neuropraxia, improvement in the palsy is expected usually within a week.

CONCLUSION: Although neonatal facial palsy is usually associated with difficult delivery it can also occur due to severe oligohydramnios as a result of compression effect on facial nerve before the onset of labour. If the examination of the newborn reveals no other abnormality supportive care for the neonate is enough as spontaneous recovery occurs with in the following week.

CONFLICT OF INTEREST: None to disclose

\section{REFERENCES}

1. Evans AK, Licameli G, Brietzke S, Whittemore K, Kenna M. Pediatric facial nerve paralysis: patients, management and outcomes. Int J PediatrOtorhinolaryngol. Nov 2005;69(11):1521-8. [Medline].

2. Falco NA, Eriksson E. Facial nerve palsy in the newborn: incidence and outcome. PlastReconstr Surg. Jan 1990;85(1):1-4. [Medline]

3. Casey BM, McIntire DD, Bloom SL, et al: Pregnancy outcomes after antepartum diagnosis ofoligohydramnios at or beyond 34 weeks' gestation. Am J Obstet and Gynecol 182:909, 2002.

4. Shapiro NL, Cunningham MJ, Parikh SR, Eavey RD, Cheney ML. Congenital unilateral facial paralysis. Pediatrics. Feb 1996;97(2):261-4. [Medline]. 


\section{CASE REPORT}

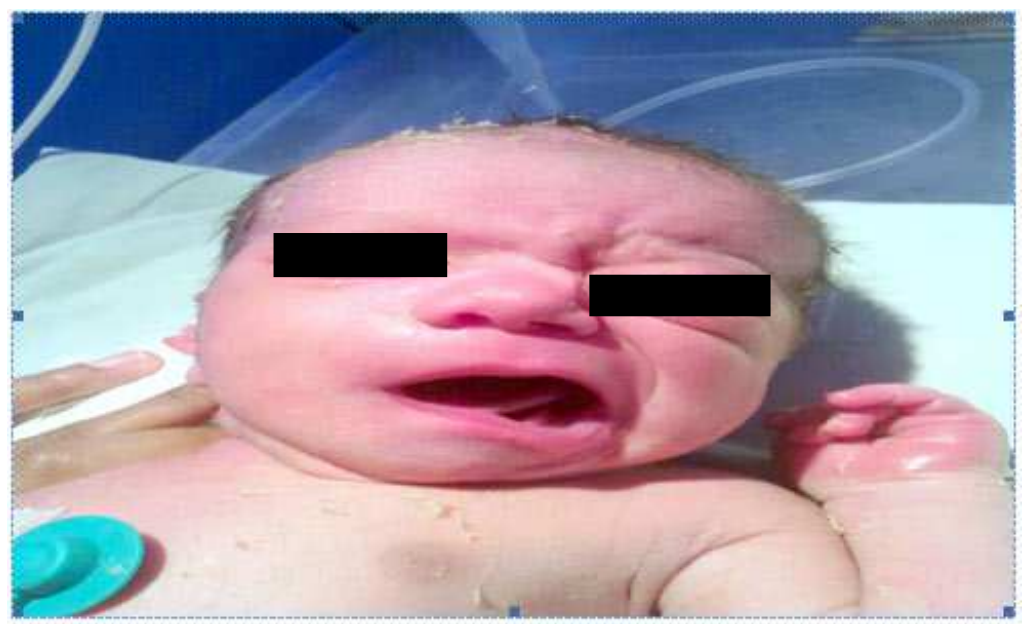

FIGURE 1-Neonatal Bell's palsy at birth

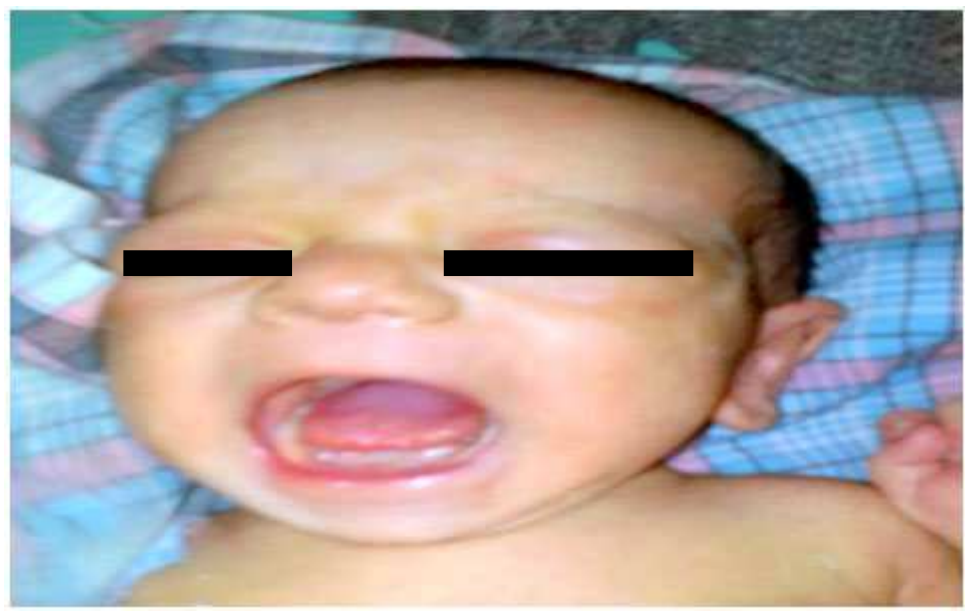

FIGURE 2-Complete recovery on $7^{\text {th }}$ neonatal day 